\title{
Design and Fabrication of a Cool Box for Passenger Car using Automotive Air-conditioning System
}

\author{
A. K. M. Parvez Iqbal* and M. M. Rahman \\ Department of Mechanical Engineering, College of Engineering, Universiti Tenaga Nasional, Jalan IKRAM-UNITEN, \\ 43000, Kajang, Selangor D.E., Malaysia; parvez@uniten.edu.my
}

\begin{abstract}
A cool box for passenger car refers to a kind of box which is designed and fabricated using well insulating materials in order to ensure the coolness inside the cool box is always stable. The coolness inside of cool box depends on the refrigerant cycles of the car air conditioning system. This cool box has same function as mini fridge to keep fresh foods and beverages but it cannot ensure to freeze the water because the temperature inside of the cool box will be in the range of $12.2^{\circ} \mathrm{C}$ to $22.1^{\circ} \mathrm{C}$ which is below the room temperature. This will help to minimize the activeness of bacteria to spoil the foods and beverages at the same time it can linger the duration for food and beverages to spoil. Cool box will help car users to bring food along them when traveling long journey and during the outdoor activities. The linkage system is mainly about connecting extra supplier hose at the receiver dryer section of car air conditioning system in order to intake the refrigerant flow to the cool box and back to connect at tube after evaporator section as outlet. All affecting parameter such as temperature inside the cool box, heat transfer rate, and air ventilation has been studied to design and fabricate the cool box. Finally several tests have been conducted which show that in operating condition inside temperature and relative humidity are suitable to keep the groceries items in fresh condition.
\end{abstract}

Keywords: Cool Box, Relative Humidity, Temperature, Insulation, Refrigerant.

\section{Introduction}

Basically the cool box for a passenger car is a kind of closed box use to keep groceries item. It acts like a mini fridge in passenger car because the coolness inside it will help food to stay fresher. Besides that, it is known that the coolness effect will slow down the activity of bacteria so it takes longer time for the bacteria to spoil the food. This cool box will get the coolness effect from the car air conditioning system by developing the linkage of refrigerant flow from car air conditioning system to the cool box which will be fixed in car luggage area. Refrigeration is the process of removing heat from an enclosed space, or from a substance, to reduce its temperature. A refrigerator uses the evaporation of a liquid to absorb heat. The liquid, or refrigerant, used in a refrigerator evaporates at an extremely low temperature, creating freezing temperatures inside the refrigerator. It is all based on the following physics: a liquid is rapidly vaporized (through compression) the quickly expanding vapor requires kinetic energy and draws the energy needed from the immediate area - which loses energy and becomes cooler. Cooling caused by the rapid expansion of gases is the primary means of refrigeration today [1]. A project by Kaynakli and Horuz was aimed to analyze and determine the performance, cooling capacity, COP value, and others output of the automotive air conditioning system in detail and experimented. In the experiment, the internal combustion engine was replaced by electric powered motor $4 \mathrm{~kW}(5.5 \mathrm{HP})$ to drive the compressor. The electric motor speed is controlled by changing the frequency using the frequency converter and measured by optical tachometer, as well as the

*Corresponding author:

A. K. M. Parvez lqbal (parvez@uniten.edu.my) 
compressor speed. Thermocouples are placed throughout the system to measure the temperature at different locations. The experiments were carried out for different ambient, evaporator and condenser temperatures at different compressor speed. The result from the experiment is obtained from different set up and conditions to see the changes of compressor parameters. From the experiment, Kaynakli and Horuz concluded that: The cooling capacity increases, if the condenser temperature and the compressor speed increase but the COP decreases because of the compressor power consumption increases [2].

Birch described that an additional design to the normal air conditioning system, aimed for better comfort and air quality for the rear passengers, which had dual heat and air conditioning assemblies. The rear air conditioning unit consisted of an evaporator and TVX that operated in parallel flow with the front unit. Tee fittings were place in the liquid and the suction lines so that refrigerant could flow through both units, with the flow through the rear unit dependent on the cooling load. The rear evaporator was normally mounted in an assembly that includes a blower, heater core, and doors to control the air temperature and where the air returned to the passenger compartment. To minimize the operation (for front passenger only), the rear system can be shut off using the rear TXV or solenoid valve, so that less cooling load required. However, the TXV does not ensure a complete shut off and refrigerant can leak through it. Another drawback is that the evaporator will chill when the blower is shut off and the refrigerant can puddle in this portion of the suction line. The puddle can flow down the suction line and slug the compressor causing a knock and possible damage [3-5]. An alternative to avoid the above problem as well as to reduce the system cost is by using a dual zone air distribution system. In this system, no additional evaporator and hoses is required. The duct and air flow from the evaporator is split past the heater core and use two air mix valves controlled by a separate actuator. The cool air is brought to the rear compartment diffusers via ductwork. The design is complicated by the limited space allotted to them and competition with other items for this space [6].

Anyanwu designed, constructed and measured the performance of a porous evaporative cooler for preservation of fruits and vegetables. The cuboid shaped cooler was made of two different types of clay layer. Inside one was porous and outside was solid. Coconut fiber was used to fill the gap between these two layers. In order to keep the fiber in wet condition, water was supplied through a flexible pipe. The experimental result showed that the temperature of fruits and vegetables which were kept inside the cooler was around $12^{\circ} \mathrm{C}$ lower than the ambient air temperature [7].

A Joule- Thomson (JT) cold stage can be operated with a sorption compressor that basically consists of a number of cells. Activated carbon is used to fill the container of each cell. Linde-Hampson cooling cycle is established by thermally cycling the containers and at the same time controlling the gas flow through the JT cold stage. Thermodynamic study for optimization of sorption-based Joule-Thomson coolers was carried out. In this study four cooler configuration were studied where the cooler efficiency increased by a factor of 3 by the application of two-stage compression compared to single stage compression. Another factor of 3 is obtained by using an internal JT precooler. By using an external sorption cooler as a precooler gave a further improvement of 17 times larger efficiency compared to single stage compression [8-11]. A novel design algorithm is proposed for evaporative fluid coolers and closed circuit cooling towers by Nasr and Behfar. The main objective of this study is to derive a relationship among heat transfer coefficients pressure drops, heat transfer area, and mass transfer coefficient [12].

Thermoelectric cooling technology can reduce the temperatures of electronic module packages below the ambient environment temperature without the use of pumped liquid cooling or vapor- compression refrigeration cycle. The solid state refrigerators are hence particularly appropriate to the growing situation of cooling where reliability, volume and complexity are of prior consideration to the cooling coefficient of performance (COP). In addition, the stringent temperature control required by some optoelectronic components can also be provided by thermoelectric coolers (TECs), the cooling of which is readily controlled through adjusting the current applied. A constant temperature or heat flux of the TEC can be maintained by the tight thermal management even if the ambient thermal condition around it varies dynamically. For these benefits, there has been an increased interest in the application of TECs to electronic and photonic device cooling. The 3D compact model of a thermoelectric cooler in the CFD approach is an essential technique for computationally realistic design for many industrial thermal management applications. The objective of this study is to develop a black-box like model for thermoelectric coolers as well as a method to formulate the effective material properties for the compact model based on the manufacturer datasheet [13-15]. 
From the above discussion it can be concluded that lot of researches are going on to improve the mechanism of cooling. This paper is focused on to develop a cool box for passenger car using the automotive air-conditioning system. Now a days the major problem facing by car users after buying groceries items from market and hypermarket to keep them inside the car in a specified area and maintain their freshness. Beside that it is difficult to avoid the bad smell which occurs from groceries item. Groceries cannot be kept fresh during the long journey because there is no commercial cool box available for this kind of application. Furthermore it is difficult to clean the luggage area in the car after been keeping with groceries item. Therefore some studies have been concentrated on design and development of this cool box to overcome the above problems using the automotive air-conditioning system.

\section{Methodology}

The process involved to design and development of the cool box is shown in Figure 1. This project is continuing with design process included detail drawing, material selection and analysis in terms of heat transfer rate within different insulating materials, COP and heat loss calculation of the cool box and identification of the process of linkage system.

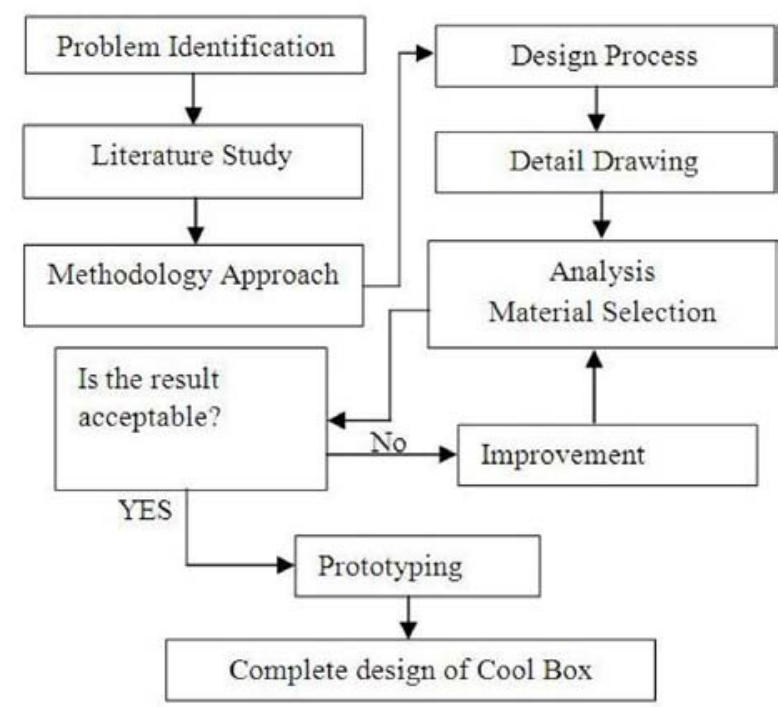

Figure 1. Design and development process.
All drawings of the cool box were made by using the SolidWorks software with the specific measurement to make sure it is suitable for fixing in the passenger car luggage area (bonnet). The Figure 2 is shown the designed cool box. The size of cool box is $0.44 \mathrm{~m} \times 0.34 \mathrm{~m} \times 0.39 \mathrm{~m}$ and the inside volume of the cool box is $0.0583 \mathrm{~m}^{3}$.

Material selection for this project is done by considering the conduction mode of heat transfer because the cool box must maintain the freshness inside of that cool box. Conduction formula states that the rate of heat flow $(Q)$ is proportional to the thermal conductivity of the material $(K)$. Therefore the materials with lowest value of the thermal conductivity must be considered during the material selection process. The heat transfer equation for conduction is expressed as

$$
Q=K A \frac{T_{1}-T_{2}}{L}
$$

Where $A$ is the surface area of heat transfer, $T_{1}-T_{2}$ is the temperature difference between two points and $L$ is the distance between points at $T_{1}$ and $T_{2}$ temperature.

For all heat conduction analysis, the basic assumptions are the condition is in steady-state and conduction is one direction which is perpendicular to the surface area. In order to obtain the total heat transfer of the cool box which is made of composite layer, thermal resistance of each layer needs to determine. Thermal resistance is expressed as

$$
R=\frac{L}{K A} \text { For conduction and }
$$

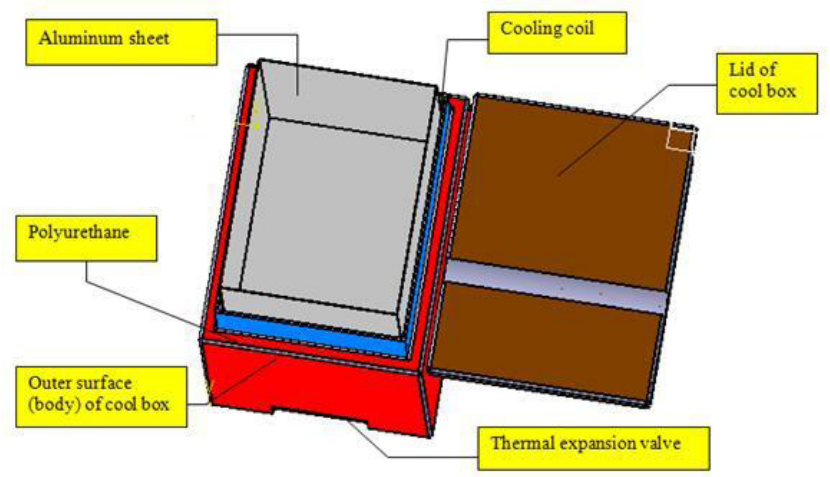

Figure 2. The Designed cool box. 
$R=\frac{1}{h A}$ For convection, where $\mathrm{h}$ is heat transfer coefficient for convection.

After obtaining the thermal resistance of the layers of different materials, coefficient of performance (COP) can be evaluated. COP is expressed as

$$
C O P=\frac{Q_{L}}{W_{\text {in }}}
$$

where $Q_{L}$ is heat absorbed in the system and $W_{i n}$ is the work input to the system.

\subsection{Automotive Air Conditioning System (Linkage System)}

According to the heat transfer physical principles, the automotive air conditioning systems works as hot air moving from the passenger compartment to the condenser and then the ambient air that moves through the coils and fins of the condenser and becomes cool. With additional blower,

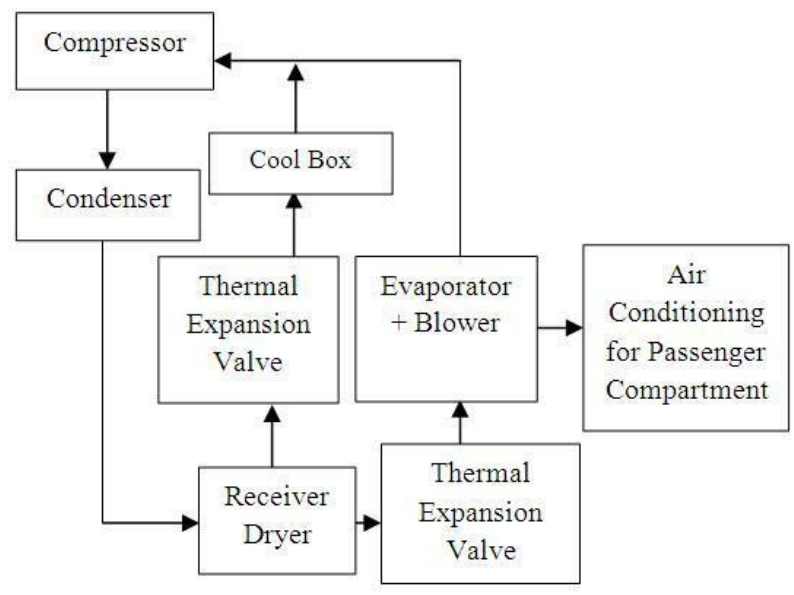

Figure 3 (a). Linkage process: option 1.

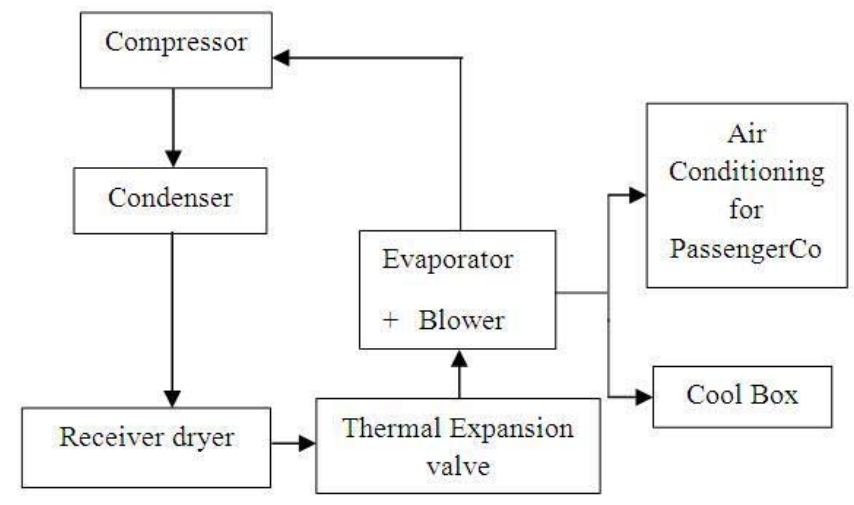

Figure 3(b). Linkage process: option 2. cool air is passed through the passenger compartment with comfort and better ventilation. The same principle can be applied in developing the mini cool box which is located in luggage area. The coolant linkage system for cool box is developed by separating channel from the front module to bring the conditioned air from blower casing to the cool box. Two linkage options are proposed for the refrigerant cycle process for the cool box as show in Figures 3(a) and 3(b).

For the first option, the refrigerant cycle refers to the process where the refrigerant (R-134a) is moved to linkage from the receiver dryer of automotive air conditioning system and flowed through tube which is connected to the inlet capillary tube of cool box before entering the thermal expansion valve. Then the refrigerant is flowed through the coil of capillary tube which has developed at inside wall of cool box. After flowing through the coil, it is exited from cool box through a tube which is connected after evaporator and blower part of automotive air conditioning system. Therefore the refrigerant is flowed back through every component in automotive air conditioning system. This process is repeated as a cycle to ensure the heat inside of cool box is rejected through the flow of refrigerant in form of vapor. For the second option, the refrigerant cycle refers to process where the refrigerant (R-134) is moved to the linkage after evaporator and directed to the cool box. The cool air from the evaporator is entered the cool box by flowing through the air flow tube which has developed inside the wall of cool box. After flowing through the air flow tube, it is exited from cool box and connected

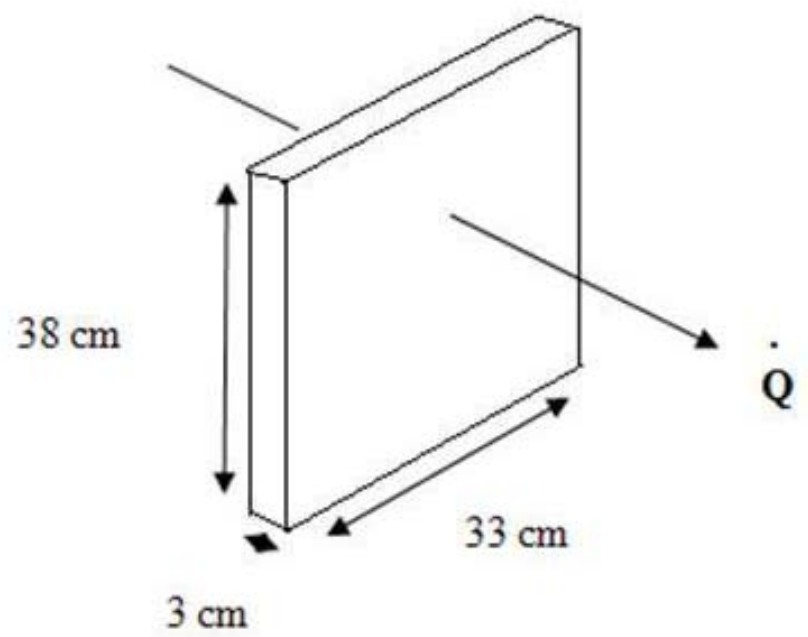

Figure 4. Heat flow through wall. 


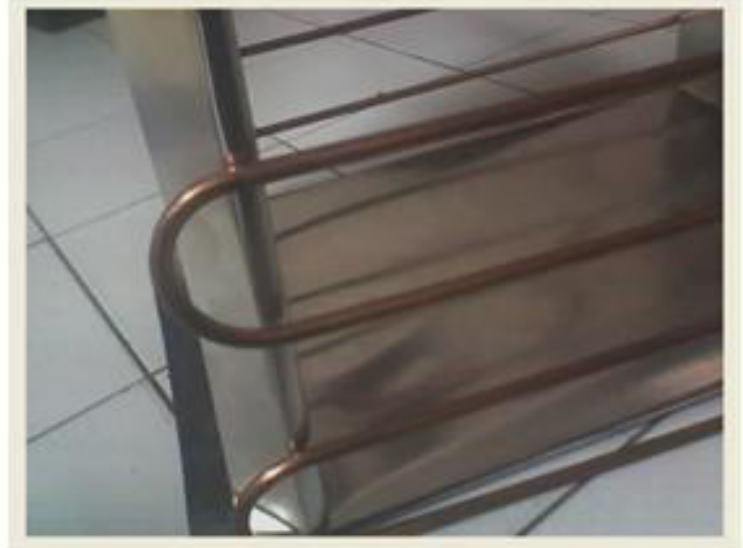

Cooling coil

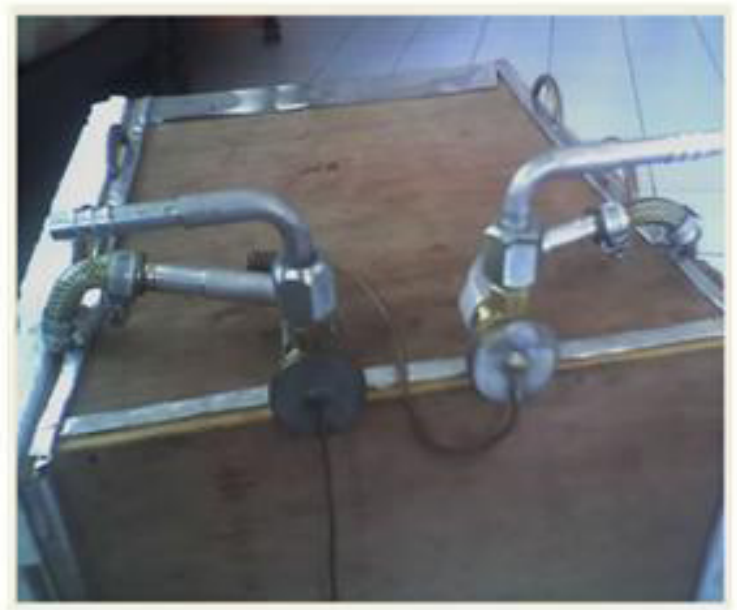

Expansion valve

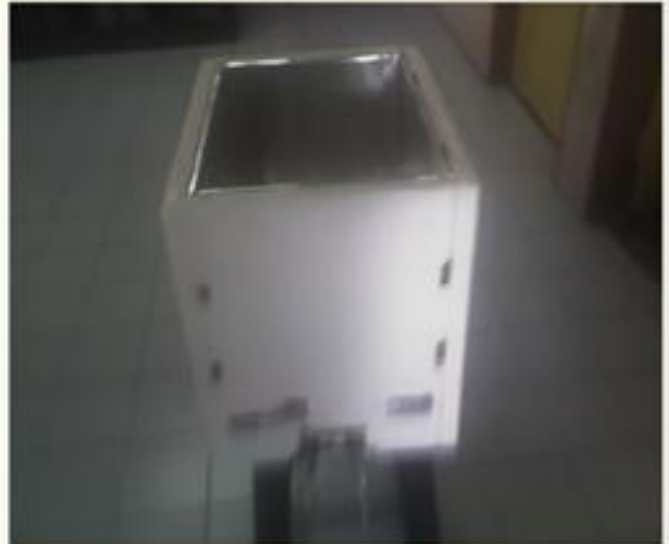

Polyurethane insulation

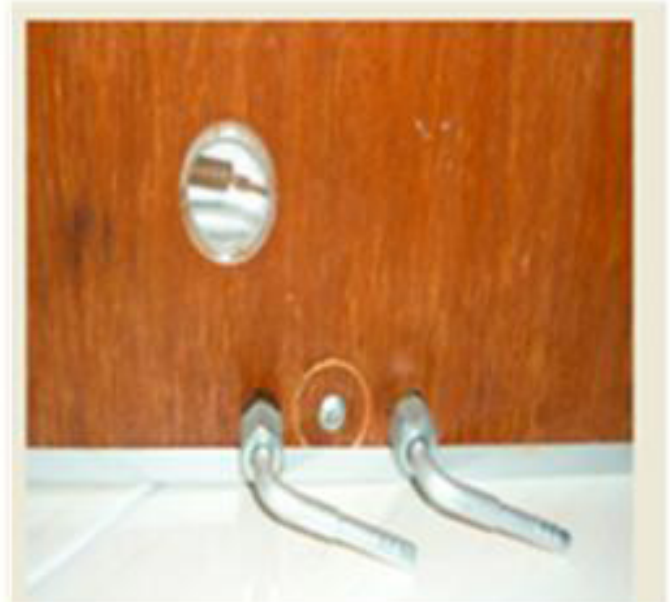

Final product of cool box

Figure 5. Developed cool box.

to tube after evaporator and blower part of automotive air conditioning system. This process will be repeated as a cycle to ensure the heat inside of cool box is rejected through the flow of refrigerant in vapor form. After consider the cost and time factor, option 1 has been chosen to develop the linkage system to cool box.

\section{Result and Discussion}

\subsection{Material Selection}

The materials which are selected for this project are polyurethane, ceramic porcelain and PVC. The thermal conductivity, $\mathrm{k}$ for polyurethane is lowest compare to ceramic porcelain and PVC. Meanwhile from survey the cost for polyurethane is lowest than the other insulation material. Polyurethane is easy to fabricate rather than ceramic porcelain. Furthermore polyurethane is widely used in flexible and rigid foams, durable elastomers and high performance adhesives and sealants, fibers, seals, carpet underlay, and hard plastic parts. For the outer surface (body) wood has been selected and for the inner surface aluminum has been chosen. The selection of this two materials are done by consider the cost and the thermal conductivity. The theoretical analysis is done according to important aspects which considered while developing this cool box. The calculation mainly focuses on two aspects that are in thermodynamics and heat transfer field. Figure 3 shows the dimensions of the wall of the cool box for heat transfer and Table 1 show the thermal conductivity and the heat transfer of the selected materials.

From Table 1 it is seen that the heat transfer through the polyurethane material is less than the heat transfer through 

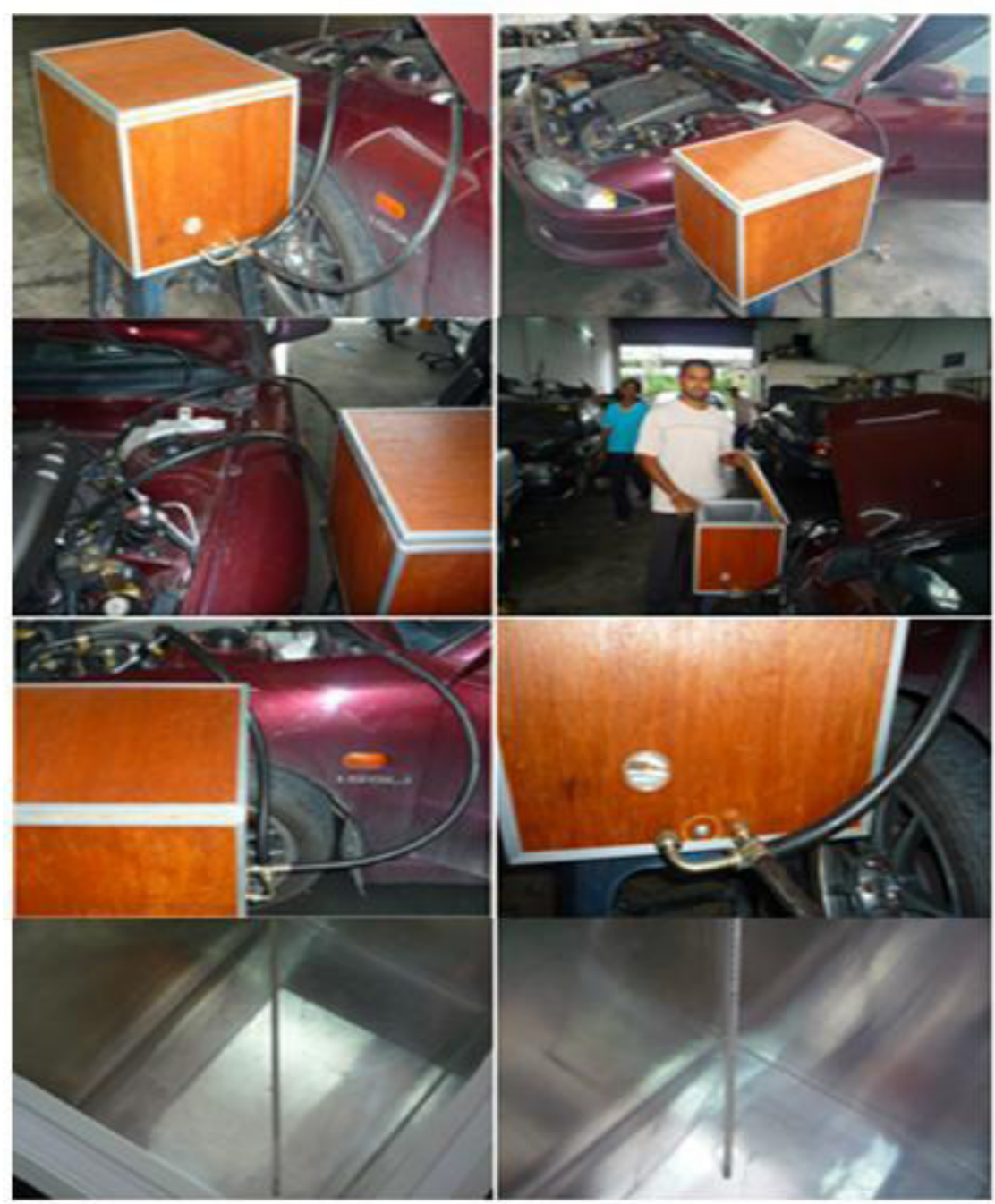

Figure 6. Testing setup.

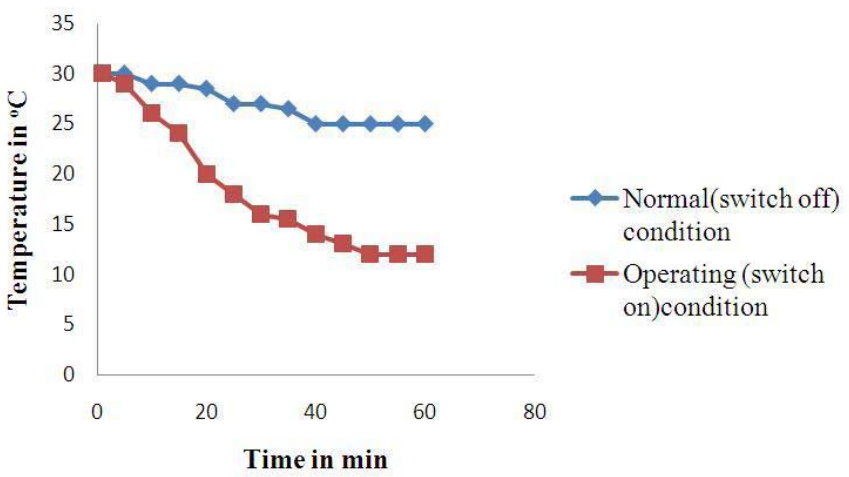

Figure 7. Temperature corresponding to time in normal and operating condition.

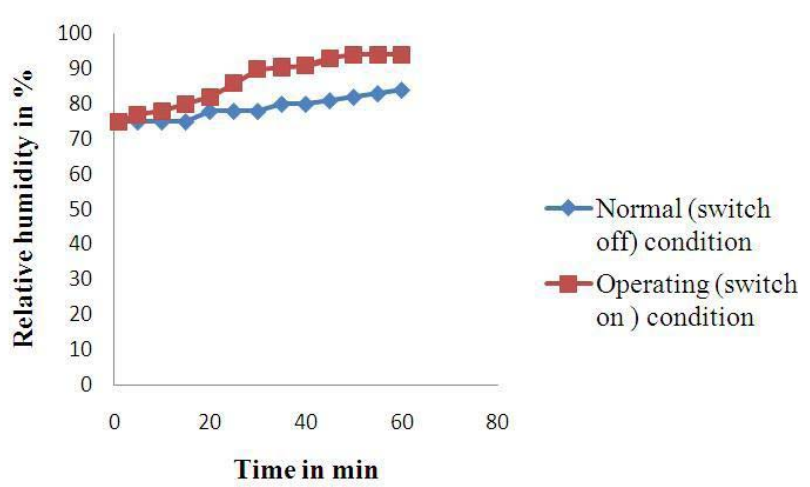

Figure 8. Relative humidity corresponding to time in normal and operating condition. 


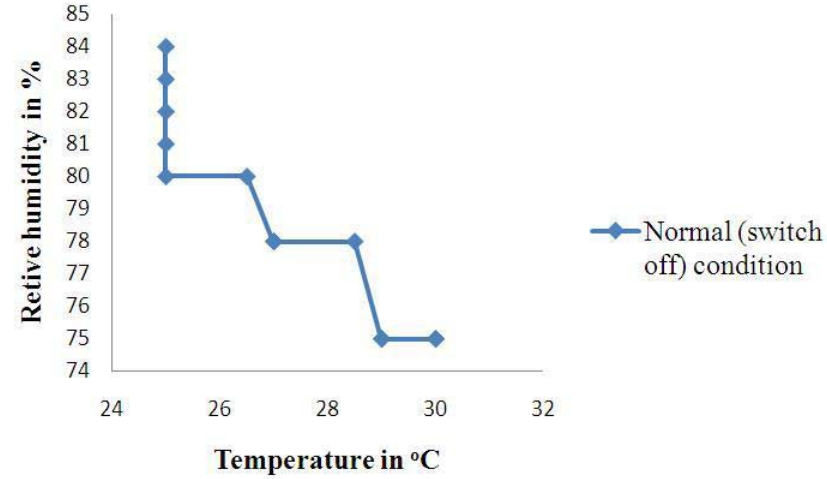

Figure 9. Relative humidity corresponding to temperature in normal condition.

the polyvinyl chloride (PVC) and ceramics porcelain. Therefore, polyurethane is much better insulation that can be used to fabricate the inside part of the cool box.

The construction of the cool box walls includes wood $(2 \mathrm{~cm})$, aluminum sheet $(0.1 \mathrm{~cm})$, and polyurethane $(3 \mathrm{~cm})$ which have thermal conductivity values of $0.12 \mathrm{~W} / \mathrm{m} . \mathrm{K}$, $222 \mathrm{~W} / \mathrm{m} . \mathrm{K}$ and $0.029 \mathrm{~W} / \mathrm{m} . \mathrm{K}$ respectively. The COP of the cool box is about $1.4 \%$ and the total heat rejection of the walls of the cool box is about $765.20 \mathrm{~W}$.

\subsection{Development of Cool Box}

Development of cool box is done by considering the design analysis and material selection. The steps of development of cool box are described as follows:

Figure 5 shows the developed cooling coil which is made by copper tube. The cooling coil is developed in both side of cool box to make sure that the coolness inside the cool box is uniformly distributed.

The insulation of the cool box is made by polyurethane as shown in Figure 5. Because of this polyurethane insulation, the coolness inside the cool box remains stable and reduces the heat transfer through the cool box. The thermal expansion valve fixes with the cooling coil to make sure pressure of the refrigerant is dropped before entering the cooling coil. Refrigerant R-134a is used for the cool box.

\subsection{Testing Performance of the Cool Box}

Performance test of the cool box is carried out in normal (switch off) and operating (Switch on) condition. Figure 6 shows the test set up during the performance test.

Figure 7 shows the temperature corresponding the time in normal and operating condition. In normal condition,

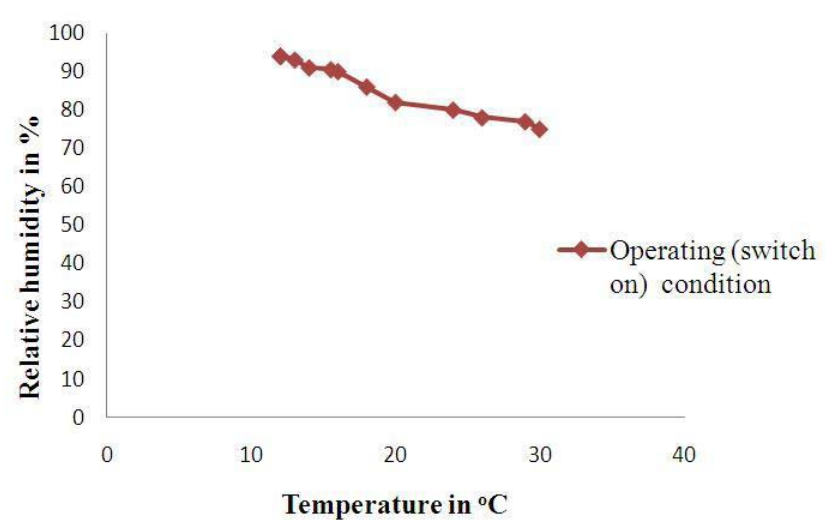

Figure 10. Relative humidity corresponding to temperature in operating condition.

the temperature decreases as the time increases but after some times the temperature becomes constant. It implies that once the cool box temperature reaches to the room temperature, it becomes constant. In this experiment temperature becomes constant of $25^{\circ} \mathrm{C}$ from $40 \mathrm{~min}$. On the other hand during operating condition, temperature also decreases as the time increases and it is significantly lower than the room temperature. The lowest temperature is about $12^{\circ} \mathrm{C}$ is obtained during the test.

Figure 8 shows the relative humidity corresponding to the time. In normal condition the relative humidity gradually increases as the time increases but at the same time inside temperature of the cool box is about $25^{\circ} \mathrm{C}$. It implies that in normal condition as the time increases the inside condition would be damped. On the other hand in operating condition though the humidity increases as the time increases, but the inside temperature is significantly lower than the room temperature. It implies that the inside condition is cold and fresh enough to keep the groceries products.

Figure 9 and 10 represent the relative humidity corresponding to the temperature in normal and operating condition respectively. In normal condition the relative humidity increases as the temperature decreases until the inside temperature reaches to the room temperature. Once the inside temperature reaches to room temperature, the relative humidity becomes constant. It implies that the inside condition is not suitable to keep the groceries products. Because after a certain period, the groceries products would start releasing heat, that would increase the inside temperature as well as the relative humidity. In operating condition the temperature gradually decreases as the relative humidity increases. Since the inside temperature is 
Table 1. Selected materials, their thermal conductivity and corresponding heat transfer

\begin{tabular}{llcc}
\hline \multicolumn{1}{c}{ Material } & Type of material & $\begin{array}{c}\text { Thermal } \\
\text { conductivity, } \\
\text { K in W/mK }\end{array}$ & $\begin{array}{c}\text { Heat } \\
\text { transfer, Q } \\
\text { in W }\end{array}$ \\
\hline $\begin{array}{l}\text { Ceramic } \\
\text { porcelain }\end{array}$ & $\begin{array}{l}\text { A non-metallic } \\
\text { material }\end{array}$ & 0.071 & 5.31 \\
$\begin{array}{l}\text { Polyvinyle } \\
\text { Chloride } \\
\text { (PVC) }\end{array}$ & $\begin{array}{l}\text { An insultions } \\
\text { or plastification } \\
\text { material }\end{array}$ & 0.100 & 7.48 \\
$\begin{array}{l}\text { Polyurethane } \\
\text { An insulation } \\
\text { material }\end{array}$ & 0.029 & \\
\hline
\end{tabular}

significantly lower than the room temperature and relative humidity is more that $90 \%$ which can keep fresh the groceries products.

From the results of actual data which have shown a good prospect for this kind of cool box because minimum temperature reaching to $12^{\circ} \mathrm{C}$ when testing the cool box by switching on automotive air conditioning system rather normal condition. Therefore, this cool box definitely can develop for marketing purpose because it has achieved the main objective that is to maintain the freshness of groceries items inside of the cool box.

\section{Conclusion}

The cool box is fabricated and tested successfully. The results show that temperature and relative humidity of inside of the cool box are about $12^{\circ} \mathrm{C}$ and more than $90 \%$ which shows a good prospect for this cool box. This is because at this condition, the cool box definitely functions well to maintain the freshness of groceries item which been kept inside it. Foremost it can overcome the problem which facing by car user as minimizing the bad smell, maintaining comfort air quality inside the car and preventing the difficulty to clean the affected area after been keeping groceries items at car luggage or compartment.

\section{Acknowledgement}

The author would like to acknowledge the management of Universiti Tenaga Nasional (UNITEN) to allow him to carry out this research by providing the technical supports and equipment. The author would like to acknowledge all the members of automotive lab of College of Engineering of UNITEN for their support to conduct the test.

\section{Reference}

1. Cengel Y A, and Boles M A (2011). Thermodynamics an engineering approach, $7^{\text {th }}$ Edn., Chapter 11, New York: McGraw Hill, 610-635.

2. Kaynalki O, and HoruzI(2003). An experimental analysis of automotive air conditioning system, International Communications in Heat and Mass Transfer, vol 30 (2), 273-284.

3. Birch, T. (2003). Automotive heating and air conditioning, $3^{\text {rd }}$ Edn., Chapter 3, New Jersey: Prentice Hall, 120-155.

4. Dwiggins, B. H. (2002). Automotive air conditioning, $8^{\text {th }}$ Edn., Chapter 4, New York: Delmar, 168-196.

5. Incropera F P, and DeWitt D P (2002). Introduction to heat transfer, $4^{\text {th }}$ Edn., Chapter 3, New York: John Wiley \& Sons, 110-135.

6. William H C, and Donald L A (1998). Automotive mechanics. 10 ${ }^{\text {th }}$ Edn., Chapter 10, New York: McGraw Hill, 515-545.

7. Anyanwu E E (2004). Design and measured performance of a porous evaporative cooler for preservation of fruits and vegetables, Energy Conversion \& Management, vol 45, 13-14.

8. Wiegerinck GFM, ter BrakeHJMetal.(2007). Thermodynamic optimization of sorption-based Joule-Thomson coolers. Cryogenics, vol 37(B), 143-152.

9. Wade L A (1992). An overview of the development of sorption refrigeration, Adv. Cryogenics Eng, vol 60(1), 1095-1106.

10. Wiegerinck G F M, Burger J F et al. (2006). A sorption compressor with a single sorber bed for use with a LindeHampson cold stage, Cryogenics, vol 46(1), 9-20.

11. Burger J F, ter Brake H J M et al. (2002). Vibration- free 5 K sorption cooler for ESA's Darwin mission, Cryogenics, vol 42(1), 97-108.

12. Jafari Nasr M R, and Behafar R (2010). A novel design for evaporative fluid coolers, Applied Thermal Engineering, vol 30(17-18), 2746-2752.

13. Huang H,Weng Y et al. (2010). Thermoelectric water-cooling device applied to electronic equipment, International Communications in Heat and Mass Transfer, vol 37(2), 140-146.

14. Naphon P, and Wiriyasart S (2009). Liquid cooling in the mini-rectangular fin heat sink with and without thermoelectric for CPU, International Communications in Heat and Mass Transfer, vol 36(2), 166-171.

15. Chen M, and Snyder J G (2013). Analytical and numerical parameter extraction for compact modeling, International Journal of Heat and Mass Transfer, vol 60, 689-699. 